severe hypoxaemia under hypoxic conditions? Limited data from the literature suggest that patients with very severe obstructive lung disease (forced expiratory volume in one second of $<1 \mathrm{~L}[6]$ and/or hypercapnia [7, 8]) are at risk of severe in-flight hypoxaemia despite a good ground-level $\mathrm{Sp}, \mathrm{O}_{2}$.

Accordingly, it would also be interesting to have answers to the following questions concerning Global Initiative for Chronic Obstructive Lung Disease stage IV chronic obstructive pulmonary disease patients. 1) How many patients with a ground-level arterial oxygen saturation measured by pulse oximetry of $>95 \%$ underwent hypoxic challenge testing? 2) How many patients flew without oxygen and without preflight hypoxic challenge testing?

\section{E. Marchand}

Pneumology Unit, Mont Godinne University Hospital, Université Catholique de Louvain, Yvoir, Belgium.

\section{STATEMENT OF INTEREST}

None declared.

\section{REFERENCES}

1 Coker RK, Shiner RJ, Partridge MR. Is air travel safe for those with lung disease? Eur Respir J 2007; 30: 1057-1063.

2 British Thoracic Society Standards of Care Committee. Managing passengers with respiratory disease planning air travel: British Thoracic Society recommendations. Thorax 2002; 57: 289-304.

3 American Thoracic Society, European Respiratory Society. Standards for the Diagnosis and Management of Patients with COPD. www.thoracic.org/sections/copd/resources/ copddoc.pdf. Date last updated: November 30, 2006. Date last accessed: December 26, 2007.

4 Marchand E, Chavaillon JM, Duguet A. Quels sont les patients chez lesquels le voyage aérien comporte un risque d'insuffisance respiratoire? [Who are the patients for whom air travel comprises a risk of respiratory insufficiency?] Rev Mal Respir 2007; 24: 4S42-4S52.

5 Medical guidelines for air travel. Aerospace Medical Association, Air Transport Medicine Committee, Alexandria, Va. Aviat Space Environ Med 1996; 67: Suppl. 10, B1-B16.

6 Dillard TA, Berg BW, Rajagopal KR, Dooley JW, Mehm WJ. Hypoxemia during air travel in patients with chronic obstructive pulmonary disease. Ann Intern Med 1989; 111: 362-367.

7 Dillard TA, Moores LK, Bilello KL, Phillips YY. The preflight evaluation. A comparison of the hypoxia inhalation test with hypobaric exposure. Chest 1995; 107: 352-357.

8 Christensen CC, Ryg M, Refvem OK, Skjønsberg $\mathrm{OH}$. Development of severe hypoxaemia in chronic obstructive pulmonary disease patients at 2,438 $\mathrm{m}(8,000 \mathrm{ft})$ altitude. Eur Respir J 2000; 15: 635-639.

\title{
Prevention of ventilator-associated pneumonia: possible role of antimicrobials administered via the respiratory tract
}

\section{To the Editors:}

We read with interest the comprehensive and useful review of LORENTE et al. [1] regarding the evidence concerning measures for prevention of ventilator-associated pneumonia (VAP). The authors did not comment on the prophylactic use of antimicrobial agents administered via the respiratory tract as a potential preventive strategy for VAP. Relevant guidelines of the Canadian Critical Care Trials Group and the Canadian Critical Care Society [2] recommend against the prophylactic use of oral or intratracheal antibiotics for this purpose. However, a recently published meta-analysis of randomised controlled trials (RCTs) revealed that prophylactic administration of antimicrobials (aerosolised or endotracheally instilled) via the respiratory tract, as opposed to control treatment, was associated with a reduced incidence of pneumonia (odds ratio (OR) 0.49 ; 95\% confidence interval (CI) 0.32-0.76) in intensive care unit patients [3]. In contrast, no difference was detected with regard to mortality between the groups compared (OR
0.86 ; $95 \%$ CI $0.55-1.32$ ); the emergence of resistance associated with the implementation of this strategy was not examined due to insufficiency of the relevant available data [3].

After the publication of the aforementioned meta-analysis [3], one additional RCT on this topic has been published [4]. By comparing a prophylactic course of aerosolised ceftazidime with placebo in intubated trauma patients, the authors of the RCT reported that the number of patients with VAP was 26 $(49 \%)$ out of 53 and $26(50 \%)$ out of 52 in the prophylaxis and placebo groups, respectively [4]. We recalculated the pooled OR by adding this new information, in an attempt to update the previous meta-analysis [3]. Again, a significant difference was revealed regarding the incidence of pneumonia in favour of the prophylactic as opposed to the nonprophylactic group (OR 0.47; 95\% CI 0.24-0.91).

The potential usefulness of antimicrobials administered via the respiratory tract for the prevention of ventilator-associated 
pneumonia has been also commented upon by other experts in the field $[5,6]$. Thus, the present authors believe that the prophylactic administration of antimicrobials via the respiratory tract for ventilator-associated pneumonia deserves the attention of investigators. However, future studies should focus not only on the effectiveness of this strategy but also on safety and the issue of emergence of antimicrobial resistance.

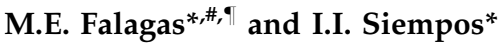

*Alfa Institute of Biomedical Sciences, and "Dept of Medicine, Henry Dunant Hospital, Athens, Greece. "Dept of Medicine, Tufts University School of Medicine, Boston, MA, USA.

\section{STATEMENT OF INTEREST}

None declared.

\section{REFERENCES}

1 Lorente L, Blot S, Rello J. Evidence on measures for the prevention of ventilator-associated pneumonia. Eur Respir J 2007; 30: 1193-1207.
2 Dodek P, Keenan S, Cook D, et al. Evidence-based clinical practice guideline for the prevention of ventilator-associated pneumonia. Ann Intern Med 2004; 141: 305-313.

3 Falagas ME, Siempos II, Bliziotis IA, Michalopoulos A. Administration of antibiotics via the respiratory tract for the prevention of ICU-acquired pneumonia: a meta-analysis of comparative trials. Crit Care 2006; 10: R123.

4 Claridge JA, Edwards NM, Swanson J, et al. Aerosolized ceftazidime prophylaxis against ventilator-associated pneumonia in high-risk trauma patients: results of a double-blind randomized study. Surg Infect (Larchmt) 2007; 8: 83-90.

5 MacIntyre NR, Rubin BK. Respiratory therapies in the critical care setting. Should aerosolized antibiotics be administered to prevent or treat ventilator-associated pneumonia in patients who do not have cystic fibrosis? Respir Care 2007; 52: 416-421.

6 Dhand R. The role of aerosolized antimicrobials in the treatment of ventilator-associated pneumonia. Respir Care 2007; 52: 866-884.

\section{Competitive swimmers with allergic asthma show a mixed type of airway inflammation}

\section{To the Editors:}

Elite swimmers are at increased risk of asthma [1]. This has been attributed to airway inflammation and increased airway responsiveness induced by high-intensity long-term exercise and repeated exposure to the chlorine-rich atmosphere in swimming pools during training and competition [2, 3] Recently, increased levels of leukotriene (LT) $\mathrm{B}_{4}$ in exhaled breath condensate and normal exhaled nitric oxide fraction ( $F$ eNO) levels have been reported in five elite swimmers, suggesting possible underlying neutrophilic airway inflammation [4]. Previous analysis of induced sputum in nonasthmatic elite swimmers showed increased proportion of eosinophils and neutrophils compared with healthy controls [3].

We aimed to characterise the airway inflammation in competitive asthmatic swimmers. Athletes from the FC Porto main swimming team and 20 nonathlete asthmatics were recruited; participants gave informed consent. Subjects were classified by their asthma and training status as asthmatic swimmers $(n=6$, two female, aged $17 \pm 2$ yrs, competing $8 \pm 3$ yrs, training $16 \pm 4 \mathrm{~h} \cdot$ week $\left.^{-1}\right)$, asthmatics $(n=20$, eight female, aged $14 \pm 3$ yrs) and swimmers $(n=20$, six female, aged $17 \pm 2$ yrs, competing $8 \pm 3$ yrs, training $17 \pm 3 \mathrm{~h} \cdot$ week $^{-1}$ ).

All asthmatics and nine (45\%) of the swimmers were atopic according to skin-prick test results. None smoked. During two visits to the clinic, 1 week apart, subjects' sputum cell counts, FeNO, lung volumes and airway responsiveness to methacholine (provocative dose causing a $20 \%$ fall in forced expiratory volume in one second (FEV1); PD20) were determined. Sputum cell counts were further compared with reference values from a group of healthy schoolchildren $(n=15$, five female, aged $9 \pm 2$ yrs, $40 \%$ atopic) [5].

Sputum was examined as described previously [3]. Briefly, after induction using an inhalation of hypertonic saline, sputum was selected and treated with dithiothreitol (Sputolysin ${ }^{\circledR}$; Calbiochem Corporation, San Diego, CA, USA). The suspension was centrifuged and the cell pellet was resuspended. Cytospins were prepared and stained using May-Grünwald/Giemsa. Differential cell counts were made by counting a minimum of 500 nonsquamous cells. FeNO was measured by chemiluminescence (NIOX; Aerocrine, Stockholm, Sweden) and PD20 methacholine was determined using the dosimeter method, according to recommendations [6, 7]. ANOVA was used to detect differences between groups. Due to the skewed distribution, eosinophil counts and PD20 methacholine comparisons were made after logarithmic transformation. In order to permit analysis in the log scale, a constant (0.01) was added to each value to eliminate 0 values. A p-value $<0.05$ was considered to be stastically significant.

Induced sputum samples of asthmatic swimmers showed increased numbers of eosinophils and neutrophils compared with both healthy subjects and asthmatic patients respectively, and lymphocytes compared with healthy subjects, although the numbers were approximately the same as in swimmers or 